International Review of Research in Open and Distributed Learning Volume 18, Number 6

September - 2017

\title{
Challenges of Implementing Free and Open Source Software (FOSS): Evidence from the Indian Educational Setting
}

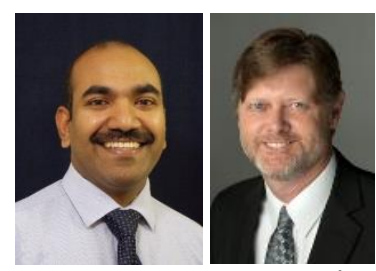

Briju Thankachan, Ph.D* and David Richard Moore, Ph.D Ohio University, Athens, Ohio *Corresponding author

\begin{abstract}
The use of Free and Open Source Software (FOSS), a subset of Information and Communication Technology (ICT), can reduce the cost of purchasing software. Despite the benefit in the initial purchase price of software, deploying software requires total cost that goes beyond the initial purchase price. Total cost is a silent issue of FOSS and can only be evaluated in the particular environment in which it is adopted, in this case Kerala, India, fora state-level FOSS project called IT@School. This project is one of the largest deployments of free open source software FOSS-based ICT education in the world and impacts 6 million students and 200,000 teachers every year. This study analyzes the perception of 43 senior FOSS implementation project officials. It details how FOSS was introduced and reports on major challenges and how those challenges were overcome in a secondary educational setting in India. Email interviews, document analysis, and online case studies were used to collect the data. The lack of adequate resources to train the teachers was the single biggest challenge in the adoption of FOSS. The emerging strategies for efficient FOSS implementation could be used in other states in India and in other developing countries.
\end{abstract}

Keywords: FOSS, ICT, India, Kerala, IT@School

\section{Introduction}

ICT can create a competitive edge in the education sector by customizing teaching and learning to meet students' needs (Scheuermann \& Pedró, 2010). However, the cost of technology, including the purchase of software (Anderson \& Dexter, 2005; Pelavin Research Institute, 1997), is a major barrier for technology 
implementation. One solution to high software costs might be Free and Open Source Software (FOSS), as " $[t]$ he fundamental freedom of being able to use, distribute, modify, and redistribute the modifications made to software released as FOSS, as well as the availability of FOSS without licensing fees and with source code" (Hoe, 2006, p. 7) is leading governments, corporations, and academia to move from proprietary or commercial software to FOSS.

The latest statistics show that in 2015, there were more than 430,000 FOSS projects registered around the world with over 3.7 million users (SourceForge, 2015). In this transition from commercial software to free software, it is important to understand that FOSS has systemic effects and is more than a software engineering phenomenon (Feller, Fitzgerald, Hissam, \& Lakhani, 2007). Even though FOSS has the potential to enhance the education sector, the prediction of Roger's Diffusion of Innovation is often substantiated: "Getting a new idea adopted, even when it has obvious advantages, is difficult" (Rogers, 2003, p. 1). This study describes a state-level project, the IT@School in India, to understand how FOSS was implemented; it deals with barriers faced by the Kerala education sector to implement FOSS-based technologies in high schools and how it overcame those challenges.

The primary research questions of this study were the following:

- What are the barriers and resource challenges to implementing FOSS-based education in schools in Kerala, India?

- Which strategies are employed by the IT@School project officials to overcome these barriers?

\section{Background}

The term Free and Open Source Software (FOSS) emerges from the convergence of two organizations, Free Software Foundation (FSF) and Open Source Initiative (OSI). FSF takes a value stand on software development and distribution, while OSI promotes the economic and practical side of Open Source Software (Free Software Foundation [FSF], 2015; SourceForge, 2015). The OSI certified software guarantees the right to modify, distribute, and use the software freely. In literature, the concept of FOSS has been used interchangeably as Open Source Software (OSS), Free Software, and Libre Software. However, terms such as Freeware Software and Shareware Software do not come under the FOSS definition. Shareware Software is sometimes distributed without a cost, but for full legal use, it usually requires additional payment and registration while the software authors retain content copyright. Similar to Shareware, Freeware Software authors retain authors' content copyright and distribute the software's full potential at minimal cost and without support (Knowledge Base, 2013). Ghosh (2007) points out that many writers in Europe use the term Free/Libre/Open Source Software (FLOSS). The United Nations Educational, Scientific and Cultural Organization (UNESCO) uses the term FOSS. The present study also uses the term FOSS.

\section{Potential of FOSS}


The potential of using FOSS has been widely investigated. The major benefits are related to cost, reliability, extendibility, and security (Ajila \& Wu, 2007; AlMarzouq, Zheng, Rong, \& Grover, 2005; Surman \& Diceman, 2004). Among the benefits, cost is one of the major driving forces behind the FOSS projects. Studies have shown that FOSS integration reduces costs, and this is the main motivation of the deployment of FOSS (Ajila \& Wu, 2007; AlMarzouq et al., 2005; Feller et al., 2007). In the software development field (e.g., Ajila \& Wu, 2007) the FOSS-based development model reduces cost and risk and improves productivity and quality. The importance of localization of content, lack of customized tools for teaching and learning, and funding problems are motivating educators in Europe to embrace this technology (Gonzalez-Barahona, \& Robles, 2006). FOSS also plays an important role in bridging the digital divide by providing low-cost applications that have the ability to localize content particularly in developing countries in Africa, Asia, and Latin America (Hoe, 2006).

\section{FOSS in Indian Educational Settings}

In India, the majority of secondary school curricula are oriented toward proprietary products (e.g. Microsoft Office, Visual Basic, and SQL Server). FOSS-based education is still in its infancy. However, the government of India and corporations are taking steps to improve the quality of education by adopting FOSS projects. Following the guiding principles of the 2005 National Curriculum Framework (e.g., connecting knowledge outside the classroom, enriching the curriculum beyond the textbook), several programs have been initiated to integrate FOSS-based education in K-12 settings. The Centre for Development of Advanced Computing (C-DAC) is an Indian government agency; its open source software division develops software that can be applied indifferent sectors. For example, in cooperation with IBM, C-DAC developed the RE portal, which helped to reinvent the education process in India. In cooperation with the Central Board of Secondary Education (CBSE) C-DAC initiated a project called Trainers Training and Student Talent Transformation. This project creates an eLearning repository for math, scienc,e and FOSS lab where students can do innovative projects (Center for Development of Advanced Computing [C-DAC], 2015b; DEIT, 2015).

In 2005, the government of India, in cooperation with the Department of Information Technology (DIT) and the Ministry of Communication and Information Technology (MCIT) established the National Resource Centre for Free/Open Source Software (NRCFOSS). The mission of this agency is to provide resources to FOSS-related projects in the country. One of the major challenges to adopting FOSS in India is the lack of support staff (Sharma \& Adkins, 2006). Though India has the labor force, FOSS-based training is lacking. To increase FOSS-trained labor force, NRCFOSS has implemented FOSS-based teaching in the engineering curriculum with a vision to produce a large number of engineering graduates with exposure, training, and skills in FOSS technologies. In addition, other certification and validation programs have been initiated to provide informal FOSS training. Industries are also joining to strengthen FOSS-based education and support. For example, several companies (e.g., Red Hat, Novell, IBM, and Intel) have opened FOSS resource centers in different parts of India to provide internship programs to engineering students. Intel, in cooperation with the Department of Information Technology, has opened a FOSS resource center to integrate ICT in curriculum development (C-DAC, 2015b; National Resource Centre for FOSS [NRCFOSS], 2013). 
An example of a FOSS initiative in India is Bharat Operating System Solutions (BOSS). BOSS is an Indian version of a GNU/Linux-based operation system (http://www.bosslinux.in), developed by C-DAC and delivered by NRCFOSS. The desktop environment of this operating system supports 18 Indian languages; this encourages the non-English literate to adopt FOSS. BOSS has been widely used in government and educational settings. For example, EduBoss, part of the BOSS operating system, incorporated educational applications (e.g., educational games, graphic tools) as well as open office, which supports 22 Indian languages (C-DAC, 2015a; DEIT, 2015).

The Ministry of Human Resources Development (MHRD) introduced several free educational resources in recent years. To provide universal access in secondary education, the government of India launched Rashtriya Madhyamik Shiksha Abhiyan (RMSA) in 2009. One of the objectives of the RMSA is to implement ICT enabled education in secondary level education (Ministry of Human Resource Development [MHRD], 2016). In 2015, the Ministry of Human Resources Development (MHRD) launched an online portal called e-basta for schools and students to browse e-books free of charge (C-DAC, 2015c). Open Source Courseware Animations Repository (OSCAR) provides interactive animations for math and science topics (Open Source Courseware Animations Repositor [OSCAR], 2010). To reduce the dependency of commercial software in education, the MHRD started a project called Free and Open Software in Education (Free and Open Software in Education [FOSSEE], 2009). National Mission on Education through ICT (NME-ICT) created e- content for master's courses called e-PG pathshala (Information and Library Network [INFLIBNET], 2016). MHRD started another project called Creating Digital Learning Environment for Design in India ('ekalpa') (e-Kalpa, 2016).

\section{Context of the Study}

Kerala is a state in India, a 392-mile-long $(631 \mathrm{~km})$ strip of land in the southern part of the country. The total population in the state is $33,406,061$. Kerala is the most literate state in India. As per the 2011 census, the effective literacy rate was $94 \%$. Furthermore, Kerala has made remarkable progress on all social development indicators, such as access to basic education and medical facilities (Government of Kerala, 2016).

\section{Education Sector}

At present, there are 12,271 schools in Kerala, 55\% which are lower primary schools (LP) $24 \%$ which are upper primary schools (UP), and 21\% which are high schools (HS). Among the schools, 36\% are government schools (2551 LP, 957 UP, and 984 HS), 59\% are private aided schools (4003 LP, 1870 UP, and 1409 HS), and $4 \%$ are private unaided schools (158 LP, $124 \mathrm{UP}$, and $215 \mathrm{HS}$ ). There are 102 teacher-training institutes, 43 schools for children with special needs, and eight Anglo-Indian high schools. The State Council of Educational Research and Training (SCERT) was established in 1994 as an autonomous organization by reorganizing the State Institute of Education (SIE) to provide academic support to general education in the states (General Education Department, 2014).

\section{About IT@School}


The IT@School is a project under the Directorate of Public Instruction of the government of Kerala, India. This project integrates ICT as part of the teaching and learning for improvement of conventional teaching and learning systems. IT@School is one of the largest deployments of FOSS-based ICT education in the world. The main activities of the project are capacity building, infrastructure development, content development, and E-government. IT@School has three project partners - the government of India, Indian Space Research Organization (ISRO), and the Department of General Education in Kerala. The government of India funds the project. ISRO supplies the technology for EDUSAT. The Department of Education implements the project. Other supporting partners for this project are BSNL, Linux, Intel, and several nongovernmental organizations (IT@School, 2014; Sadath, 2012).

\section{Method}

Data were collected from three sources: email interviews, document analysis, and an online case study form. In the email interview process, a senior project official was available to answer the email interview questions. The general idea about the project was collected through email interviews with open-ended and focused questions about the implementation and evaluation of the project. As part of the document analysis, documents (e.g., project reports) were collected from the IT@Schools senior officials, Kerala's educational department websites and the Ministry of Education website.

An online case study form was used to collect primary data. The form was modified from the case study form from the Office of Educational Technology (OET) of the New Hampshire Department of Education. The case study form had six sections: general information, program category, initial planning and implementation, evaluating effectiveness, making improvements, and sharing benefits. The general information section provides details about the project name, contact info, start date, and brief project description. In the program category, participants were asked to indicate and rank the best category of the project. The program categories were access to technology, technology literacy for all students, professional development, and community.

Under the initial planning and implementation category, participants were asked to rank the biggest planning and implementation challenge. This was completed by follow-up question on how they overcame those challenges. In evaluating effectiveness, participants were asked to rank the most effective teaching approaches supported by the FOSS project and the data collected to evaluate the project. In addition, participants were asked to rank the essential conditions necessary for the success of the project. The question "How would you change the way you implement this project in the future?" was asked in the making improvements category. In the sharing the benefits category, the question was "What recommendation do you have for schools in other states and countries interested in replicating your project?” The executive director of the IT@School distributed the online case study form to 6o IT@School project officials and 43 of them completed the survey.

After identifying the importance or significance of each segment of information within the email interviews, documents, and case study forms, categorizing and connecting strategies were used to analyze the data (Maxwell \& Miller, 2008). As part of coding, data segments were labeled and grouped by category. The five 
final categories were the following: program category, initial planning and implementation, evaluating effectiveness, making improvements, and sharing benefits.

\section{Results}

Since FOSS is a subset of ICT, the barriers and resource challenges to implementing FOSS-based education are similar to ICT as is reported in the literature. IT infrastructure (internet access) is very crucial for national economic development and FOSS-based projects (Koria, Bartels, Köszegi, \& Carneiro, 2012). Lack of support is one of the major challenges of ICT and FOSS implementation (Lai, 2006; Oliveira \& Martins, 2011; Woodall \& Marius, 2013). Resistance to change is one of the challenges when implementing ICT and FOSS in educational settings (Howard \& Mozejko, 2015; Kisanjara \& Tossy, 2014). Strategies employed by the IT@School project officials to overcome the barriers and resource challenges unique to FOSS are discussed in detail in the section followed by major challenges.

\section{Major Challenges}

In the case study form, the researchers asked district coordinators and master trainers to rank the challenges they had in the planning and implementation phases of FOSS. In the planning phase, infrastructure and delivery ranked first and budget ranked second. In the implementation phase, creating educational content ranked first, followed by resistance to change and lack of manpower. The age of the teachers was an important issue; young teachers were interested in learning new skills whereas older teachers resisted changes in teaching. When the Department of Education incorporated FOSS in the curriculum, adequate software to conduct IT practical exams for more than 140,00o high school students also brought its own challenges. Another big hurdle was starting the educational channel ViCTERS through the EDUSAT network and developing educational content. Broadband connectivity was lacking in many school departments in the initial stage of the project. Table 1 shows a comparison of the major challenges in the planning and implementation phases.

Table 1

Major Challenges in Planning and Implementation of FOSS

\begin{tabular}{llll}
\hline \multicolumn{2}{l}{ Planning phase } & \multicolumn{2}{l}{ Implementation phase } \\
\hline Ranking & Challenges & Ranking & Challenges \\
\hline 1 & Infrastructure & 1 & Creating educational content \\
2 & Budget & 2 & Lack of manpower \\
3 & Project risk & 3 & Resistance to change \\
4 & Standards or compliance & 4 & Lack of adequate software \\
5 & Other- ICT enabled material production & 5 & Lack of real-time collaboration
\end{tabular}




\section{Strategies Used to Overcome Challenges to Implement FOSS}

In the case study form, the researchers asked the open-ended question, "How did you overcome the challenges in the planning and implementation phases?" A common theme from all the answers was teamwork because it reduced the project risk. In the planning phase, a timeline for task management was created for each of the activities. In addition, ideas and responsibilities were shared among the group members from time to time. The following sections discuss in depth the strategies used to overcome challenges.

\section{Lack of Infrastructure and Budget}

Schools in Kerala lack classrooms with electricity, computer labs, and telecommunication facilities. Grants from state and federal agencies helped to overcome the lack of infrastructure. As project partners, the government of India and the state government provide funds for infrastructure. The Indian Space Research Organization (ISRO) supplies technology for satellite-based education and the government-owned telephone company provides broadband connection to the schools.

\section{Creating Educational Content}

Teachers record their subject-related content at school level and present to students through LCD projectors, CDs, and ViCTERS. For example, lectures of good math teachers are video -recorded and shared with other teachers and students in the state. In order to produce localized content, IT@School distributes a semi-professional Panasonic Handicam or video camera to each school district. The project conducts workshops on creating educational content (lecture videos, etc.) for school teachers. Some film makers volunteer to help with the educational department initiative to create local content. All the educational content developed by the project and telecasted through ViCTERS channel is bilingual (English and Malayalam). The teachers from the Malayalam medium of instruction record the content for subjects in Malayalam. Instructors of the English medium record the content in English.

\section{Lack of Manpower}

Temporary manpower was created by selecting coordinators from each school. These coordinators became school student IT coordinators and teacher IT coordinators. These coordinators served as the immediate IT support for teachers and students. Student IT coordinators teacher IT coordinators were given periodic workshops and trainings from the IT@School. The following text is an extract from a respondent:

Lack of manpower is solved by recruiting trainers on a work arrangement basis and developing one teacher from each school as leader of all the activities of that school. By all these types of methods naturally the resistance became less and feeble.

In addition, the project received resource personnel from the Free Software Foundation of India. To train high school teachers and reduce their reluctance, the project established resource centers in Kochi, and 
EDUSAT training centers in each district. In the first phase, 40,000 teachers were trained over 90 hours on Linux-based operating systems.

\section{Lack of Adequate Software}

The project developed a free operating system based on the Linux version Ubuntu called IT@School GNU Linux. Now it has three updated versions, the latest being IT@School GNU Linux version 3. This free platform helped to create a single curriculum. The IT@School GNU Linux version 3 platform was created through funding from the Kerala IT@mission. The Society for Promotion of Alternative Computing and Employment (SPACE) was a solution to this problem. SPACE decided to offer support to IT@School and established a resource center for conducting teacher training with technical assistance.

\section{Lack of Real-Time Collaboration}

The lack of real-time collaboration was due to poor connectivity. The connectivity issue was solved in three ways. Firstly, the government-managed telephone company BSNL agreed to provide broadband connectivity to all government schools with an annual rate per connection of Rs 5,000 (\$100). Now 20\% of the schools have wireless connections. Secondly, as part of the national e-governance plan (NeGP), the government of Kerala has a network called Kerala State Wide Area Network (KSWAN). IT@School uses this connectivity at a centralized level for the automation process. Finally, the EDUSAT satellite provides broadband network to all schools through interactive IP-based technology. To facilitate this channel, the state has 95 Satellite Interactive Terminals (SIT) and 300 Receive Only Terminals (ROT). These channels reach households through local channels. These channels are used for video conferencing, tele-training, and distance education.

\section{Essential Conditions Necessary for Success of a Project}

Participants were asked to respond to this statement: "From the following list, identify the essential conditions necessary for success of your project." Leadership and support system ranked first and infrastructure ranked second.

\section{Project-Supported Effective Teaching Approaches}

According to master trainers and district IT coordinators, empowering students was the most important teaching approach, followed by fostering learners' interactions. Flexibility ranked third and enhancing traditional material ranked fourth. Figure 1 shows the pie chart of effective teaching approaches. 


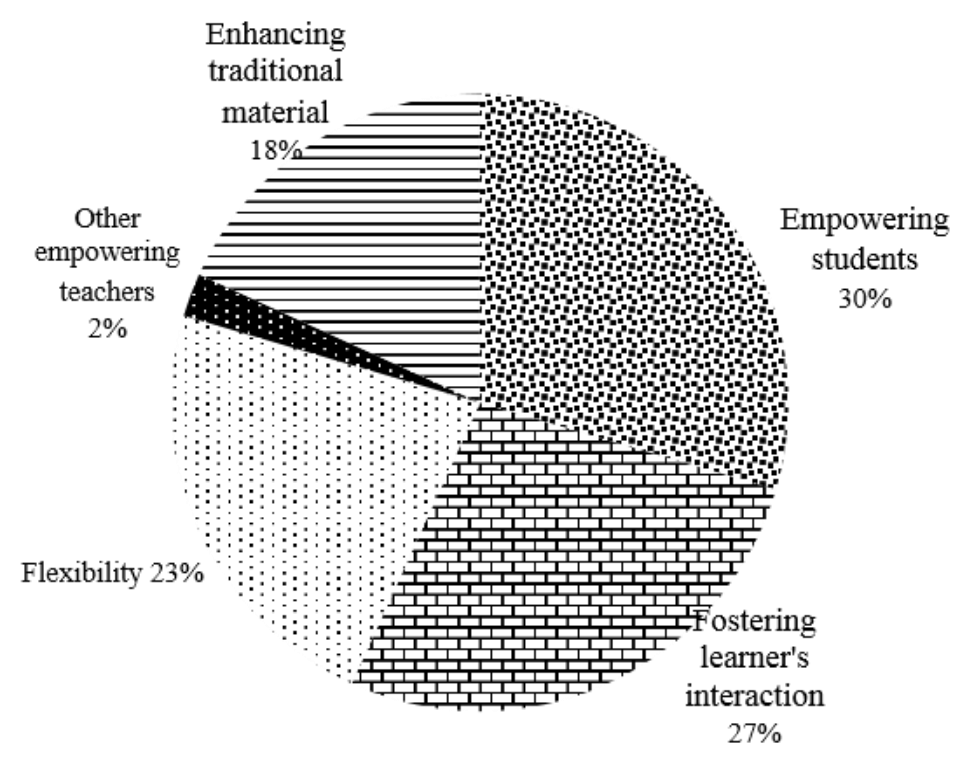

Figure 1. Effective teaching approaches.

\section{Future Plans and Sustainability}

As part of future plans and sustainability, the researchers asked the following question: "How would you change the way you implement this project in the future?" A theme that emerged from the answers was using ICT-enabled education as opposed to IT-based education. From 2001 to 2010, the focus of the project was on IT education. In IT education, students were merely learning different functions and parts of ICT. The ICT-enabled education aims to enhance teaching and learning with more interactive tools like wikis, blogs, podcasts, and subject-based software applications. Presently, mathematics is the major content area addressed by the IT@School project. Future plans involve using more free software applications in other subjects and learner-centered learning activities. The following text is an extract from a respondent's opinion: "We plan to check out the limitations and opportunities in each school in implementing ICT education and take steps accordingly to provide good learning experience to students as well as to update teachers." Creating a research wing in the content development area is part of the project's plan because the project does not have this yet. The project has a centralized purchasing mechanism for purchasing hardware. These systems are helping to keep similar hardware throughout the state.

The project can be sustained in the future because of its adaptability to embrace new technologies. In addition, the teachers are receiving refresher courses. IT content and other subjects are periodically modified in accordance to the curriculum to incorporate IT-enabled learning in teaching and learning. With expertise in the e-governance and IT training fields, the project plans to conduct certified courses in IT and is considering asking consultation fees for expertise and resource sharing. The project has already started to implement ICT-enabled education in the primary and higher secondary level. The project has made a Memorandum of Understanding (MOU) with Intel to adopt the program called Teach to the Future for teacher training. This would create another 350 training centers in the state. 


\section{Students' Outcomes from the Project}

District IT coordinators and master trainers stated that there is remarkable change in the classroom. Students are becoming aware of the free software and learning basic skills about using the Internet and maintaining hardware. The following text is an extract from a respondent's feedback response:

IT@School is imparting special training to a group of students from each school as student IT coordinators meet objectives of ICT (Information and Communication Technology) functioning in schools. These students are updating school-wiki, looking after lab maintenance, and assisting teachers and other students, thus cultivating IT leaders in the student population.

The Information Technology (IT) practical exam and state IT competitions measure students' knowledge and skills. In the IT practical examination, 4.5 million students are evaluated every year through a free software platform. The State Council of Educational Research and Training (SCRET) set up guidelines to evaluate the 1oth grade IT practical examination. The practical examination is conducted by using software called "soft exam." The yearly IT competition provides an opportunity for teachers and students to show their expertise in digital painting, multimedia presentation, programming, creating IT projects, and an IT quiz.

\section{Conclusion}

This study identified major barriers to FOSS adoption in Indian educational settings and the strategies to overcome those barriers. Consistent with earlier studies (Brunvard, Luera, Marra, \& Peet, 2010; Sarrab, Elbasir, \& Elgamel, 2013; Sharma \& Adkins, 2006; Woodall \& Marius, 2013), the findings of this study confirm that the major challenges in adopting FOSS education are the lack of support systems and the need for localization of the project. Lack of support staff trained in the FOSS is one of the major challenges to adopting FOSS in India. The proprietary software applications have support readily available due to wide adoption. In addition, the employees who trained in the Unix application find it difficult to support the Linux-based application. However, in recent years, universities are incorporating FOSS-based syllabi in their engineering curriculum to train students to work with FOSS applications. Organizations are also moving into FOSS platforms that will help the industry to mature and will generate more income and eventually more efficient support systems. Localization is another major challenge in the development of FOSS projects. However, different organizations, both government, and private companies (e.g., BharateeyaOO, IndLinux, AnkurBangla, JanaBhaaratii) are in the process of creating the FOSS applications in the local languages.

Pirated software and Indian work culture is another major challenge for FOSS adoption. Pirated software is available at a lower cost compared to the original proprietary software. In India, $70 \%$ of the software is pirated (Sharma \& Adkins, 2006), which leads to little growth in the local software development market. However, India's commitment to the World Trade Organization to protect intellectual property rights is slowly changing the situation. The rigid hierarchical form of work culture is challenging the key idea of FOSS projects: collaboration. Collaboration is less valued in Indian work culture and the focus is on doing 
the assigned duty in an organizational structure. Due to the establishment of Western-based companies in India, the work culture is changing, giving more importance to innovation.

In the implementation phase, creating educational content and lack of resource personnel were the first and second biggest challenges. Seeking help from non-governmental organizations and building partnerships with private firms helped the IT@School project to overcome lack of man power. These strategies could be used in other states in India and developing countries that are in the path of FOSS-based education and improve educational practices. The findings of this study can be added to the existing literature of ICT-based education with special focus on the FOSS-based technologies in a developing country's context. The scope of the study is limited to the schools under the Kerala Department of General Education but may be useful to generalize about other states of India. Future research might target teachers, administrators, and policy makers from different states in India; that will help establish the ability to generalize this study to other contexts.

\section{References}

Ajila, S., \& Wu, D. (2007). Empirical study of the effects of open source adoption on software development economics. The Journal of Systems \& Software, 8o(9), 1517-1529.

AlMarzouq, M., Zheng, L., Rong, G., \& Grover, V. (2005). Open source: Concepts, benefits, and challenges. Communications of the Association for Information Systems, 16(1), 37.

Anderson, R. E., \& Dexter, S. (2005). School technology leadership: An empirical investigation of prevalence and effect. Educational Administration Quarterly, 41(1), 49-82. https://doi.org/10.1177/o013161X04269517

Brunvard, S., Luera, G. R., Marra, T., \& Peet, M. (2010). Implementing an open source eportfolio in higher education: Lessons learned along the way. In B. Ozkan Czerkawski (Ed.), Free and open source software for e-learning: issues, successes, and challenges. Hershey PA: Information Science Reference. Retrieved from http://site.ebrary.com/id/10428672

Center for Development of Advanced Computing [C-DAC]. (2015a). BOSS GNU/LInux. Retrieved from http://www.cdac.in/index.aspx?id=st pr Boss gnu linux

Center for Development of Advanced Computing [C-DAC]. (2015b). C-DAC Free/Open Source Software. Retrieved from http://cdac.in/index.aspx?id=st oss free open source software

Center for Development of Advanced Computing [C-DAC]. (2015c). eBasta. Retrieved from https://www.ebasta.in/content/about-ebasta

Department of Electronics and Information Technology [DEIT]. (2015). Free and open source software. Retrieved from http://deity.gov.in/content/free-and-open-source-software 
e-Kalpa. (2016). Sakshat. Retrieved from http://www.sakshat.ac.in/Document/All projects/23.html

Feller, J., Fitzgerald, B., Hissam, S. A., \& Lakhani, K. (Eds.). (2007). Perspectives on free and open source software. Cambridge, Mass.: The MIT Press.

Free and Open Software in Education [FOSSEE]. (2009). Free and open software in education. Retrieved from http://fossee.in/about-us

Free Software Foundation [FSF]. (2015). About. Retrieved from http://www.fsf.org/about/

General Education Department. (2014). School statitics. Retrieved from http://education.kerala.gov.in/index.php?option=com content\&view=article\&id=460\&Itemid=1 43

Ghosh, R. A. (2007). Understanding free software developers. In J. Feller, B. Fitzgerald, S. A. Hissam, \& K. Lakhani (Eds.), Perspectives on free and open source software. Cambridge, Mass.: The MIT Press.

Gonzalez-Barahona, J. M., \& Robles, G. (2006). Libre software in Europe. In C. DiBona, D. Cooper, \& M. Stone (Eds.), Open sources 2.o : The continuing evolution. Beijing: O’Reilly.

Government of Kerala. (2016). At a glance - Government of Kerala, India. Retrieved from https://kerala.gov.in/web/guest/at-a-glance

Hoe, N. S. (2006). Breaking barriers: The potential of free and open source software for sustainable human development - A compilation of case studies from across the world. Bangkok: NUDPAPDIP, Elsevier. Retrieved from http://www.unapcict.org/ecohub/resources/breaking-barriers

Howard, S. K., \& Mozejko, A. (2015). Teachers: technology, change and resistance. Teaching and Digital Technologies: Big Issues and Critical Questions, 307.

Information and Library Network [INFLIBNET]. (2016). e-Pg Pathshala. Retrieved from http://epgp.inflibnet.ac.in/

IT@School. (2014). IT@school Project. Retrieved from http://education.kerala.gov.in/index.php?option $=$ com $\_$content\&view $=$article\&id $=51 \& I t e m i d=59$

Kisanjara, S., \& Tossy, T. (2014). Investigating factors influencing the adoption and use of free and open source software (FOSS) in Tanzanian higher learning institutions: Towards an individualtechnology-organizational-environmental (ITOE) framework. International Journal of Research in Business and Technology, 5(2), 645-653. doi: https://doi.org/10.17722/ijrbt.v5i2.345

Knowledge Base. (2013). What are shareware, freeware, and public domain programs? Retrieved from https://kb.iu.edu/d/afdk 
Koria, R., Bartels, F. L., Köszegi, S., \& Carneiro, S. (2012). Free open source software (FOSS) and survey methodologies: The case of the Ghana national system of innovation survey. In IST-Africa 2012 Conference Proceedings, Dar es Salaam (pp. 9-11). Retrieved from http://www.innov-8.net/wpcontent/uploads/2014/07/6-Free-Open-Source-Software-FOSS-and-Survey-Methodologies.pdf

Lai, E. (2006). Lack of support slowing spread of open-source applications. Retrieved from http://www.computerworld.com/article/2561504/open-source-tools/lack-of-support-slowingspread-of-open-source-applications.html

Maxwell, J. A., \& Miller, B. A. (2008). Categorizing and connecting strategies in qualitative data analysis. In S. N. Hesse-Biber \& P. Leavy (Eds.), Handbook of emergent methods (pp. 461-477). New York: Guilford Press. Retrieved from http://books.google.com/books?hl=en\&lr=\&id=vbyxBkkjFeYC\&oi=fnd\&pg=PA461\&dq=categori zing + and + connecting + strategies + in + qualitative + data + analysis\&ots $=c N 2 k X M F i g f \& s i g=a h 4 u 7 z$ 4228NnUioGzHHN8vfSes

Ministry of Human Resources Development [MHRD]. (2016). Rashtriya Madhyamik Shiksha Abhiyan [RMSA]. Retrieved from http://mhrd.gov.in/rmsa

National Resource Centre for FOSS [NRCFOSS]. (2013). FOSS in Academics. Retrieved from http://www.nrcfoss.org.in/

Oliveira, T., \& Martins, M. F. (2011). Literature review of information technology adoption models at firm level. The Electronic Journal Information Systems Evaluation, 14(1), 110-121.

OSCAR. (2010). Open Source Courseware Animations Repository. Retrieved August 19, 2016, from http://oscar.iitb.ac.in/oscarHome.do;jsessionid=5ADBoB03C1294CFA497374C28BF9E1E8

Pelavin Research Institute. (1997). Investing in school technology : Strategies to meet the funding challenge. Washington, D.C.: U.S. Dept. of Education, Office of Educational Technology.

Rogers, E. M. (2003). Diffusion of innovations. New York: Free.

Sadath, K. A. (2012). It@school project: The kerala model of ICT education. In Mathrubhumi yearbook plus english 2012 (1st ed., pp. 496-506). Kerala: Mathrubhumi.

Sarrab, M., Elbasir, M., \& Elgamel, L. (2013). The technical, non-technical issues and the challenges of migration to free and open source software. International Journal of Computer Science Issues, $10(2)$.

Scheuermann, F., \& Pedró, F. (Eds.). (2010). Assessing the effects of ICT in education indicators, criteria and benchmarks for international comparisons. Ispra (VA): Joint Research Centre- European Commission. Retrieved from http://libproxy.cbu.ca:2048/login?url=http://dx.doi.org/10.1787/9789264079786-en 
Sharma, A., \& Adkins, R. (2006). OSS in India. In C. DiBona, D. Cooper, \& M. Stone (Eds.), Open sources 2.o : The continuing evolution. Beijing: O’Reilly.

SourceForge. (2015). About. Retrieved from http://sourceforge.net/about

Surman, M., \& Diceman, J. (2004). Choosing open source: A guide for civil society organizations. The Commons Group for the Association for Progressive Communications (APC), USA. Retrieved from http://www.commons.ca/articles/fulltext.shtml

Woodall, L., \& Marius, M. (2013). Free and open source software, open data, and open standards in the Caribbean : Situation review and recommendations August 2013. United Nations Educational, Scientific and Cultural Organization. Retrieved from http://www.unesco.org/new/fileadmin/MULTIMEDIA/HQ/CI/CI/pdf/ifap/open solutions rep ort en.pdf

\section{Athabasca} University

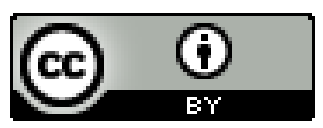

